\title{
Oncogenic HPV infection interrupts the expression of tumor-suppressive miR-34a through viral oncoprotein E6
}

\author{
XIAOHONG WANG, ${ }^{1}$ HSU-KUN WANG ${ }^{2}$ J. PHILIP MCCOY, ${ }^{3}$ NILAM S. BANERJEE, ${ }^{2}$ JANET S. RADER, ${ }^{4}$ \\ THOMAS R. BROKER, ${ }^{2}$ CRAIG MEYERS, ${ }^{5}$ LOUISE T. CHOW, $^{2}$ and ZHI-MING ZHENG ${ }^{1}$ \\ ${ }^{1}$ HIV and AIDS Malignancy Branch, Center for Cancer Research, National Cancer Institute, National Institutes of Health, Bethesda, Maryland \\ 20892, USA \\ ${ }^{2}$ Department of Biochemistry and Molecular Genetics, University of Alabama at Birmingham, Birmingham, Alabama 35294, USA \\ ${ }^{3}$ Flow Cytometry Core, National Heart, Lung, and Blood Institute, National Institutes of Health, Bethesda, Maryland 20892, USA \\ ${ }^{4}$ Department of Gynecology, Washington University School of Medicine, St. Louis, Missouri 63110, USA \\ ${ }^{5}$ Department of Microbiology and Immunology, Penn State University College of Medicine, Hershey, Pennsylvania 17033, USA
}

\begin{abstract}
MicroRNAs (miRNA) play pivotal roles in controlling cell proliferation and differentiation. Aberrant miRNA expression in human is becoming recognized as a new molecular mechanism of carcinogenesis. However, the causes for alterations in miRNA expression remain largely unknown. Infection with oncogenic human papillomavirus types 16 (HPV16) and 18 (HPV18) can lead to cervical and other ano-genital cancers. Here, we have demonstrated that cervical cancer tissues and cervical cancerderived cell lines containing oncogenic HPVs display reduced expression of tumor-suppressive miR-34a. The reduction of miR34a expression in organotypic tissues derived from HPV-containing primary human keratinocytes correlates with the early productive phase and is attributed to the expression of viral E6, which destabilizes the tumor suppressor p53, a known miR-34a transactivator. Knockdown of viral E6 expression in $\mathrm{HPV}^{+}{ }^{+}$and $\mathrm{HPV} \mathrm{s}^{+}$cervical cancer cell lines by siRNAs leads to an increased expression of $\mathrm{p} 53$ and miR-34a and accumulation of miR-34a in $G_{0} / G_{1}$ phase cells. Ectopic expression of miR-34a in

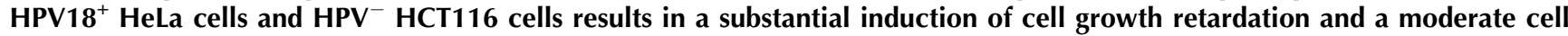
apoptosis. Together, this is the first time a viral oncoprotein has been shown to regulate cellular miRNA expression. Our data have provided new insights into mechanisms by which high-risk HPVs contribute to the development of cervical cancer.
\end{abstract}

Keywords: miR-34a; p53; human papillomavirus; E6; oncoprotein

\section{INTRODUCTION}

Human papillomavirus type 16 (HPV16) or 18 (HPV18) infection is widely recognized as a leading cause of cervical, penile, and anal cancers. Two viral oncoproteins, E6 and E7, of HPV16 and HPV18 are responsible for viral oncogenesis by destabilizing two major cellular tumor suppressors, p53 and pRb, respectively (Scheffner et al. 1990; Gonzalez et al. 2001). Tumor suppressor protein p53 functions as a transcription factor in regulating the transcription of many hundreds of protein-coding genes to safeguard the integrity of the genome by inducing cell cycle arrest and DNA repair upon encountering DNA damage, or

Reprint requests to: Zhi-Ming Zheng, HIV and AIDS Malignancy Branch, Center for Cancer Research, Room 6N106, 10 Center Drive, National Cancer Institute, National Institutes of Health, Bethesda, MD 20892, USA; e-mail: zhengt@exchange.nih.gov; fax: (301) 480-8250.

Article published online ahead of print. Article and publication date are at http://www.rnajournal.org/cgi/doi/10.1261/rna.1442309. apoptosis if repair cannot be achieved (Mirza et al. 2003; Vousden and Lane 2007; Halazonetis et al. 2008). The hypophosphorylated form of $\mathrm{pRb}$ binds to $\mathrm{E} 2 \mathrm{~F}$ family transcription factors and controls the $\mathrm{G}_{1}$-to-S transition of the cell cycle (Chellappan et al. 1992; Cobrinik 2005). Thus, destabilization of p53 and hypophosphorylated pRb by the two viral oncoproteins promotes excessive cell cycling and accumulation of mutations, leading to genome instability.

MiRNAs represent a new class of noncoding regulatory RNAs which are 21-25 nucleotides (nt) in length and modulate gene expression at the post-transcriptional level by base-pairing with complementary nucleotide sequences (seed matching) in the $5^{\prime}$ and $3^{\prime}$ untranslated regions (UTRs) of target mRNAs (Grimson et al. 2007; Lytle et al. 2007; Nielsen et al. 2007). Approximately 416 miRNA genes have now been identified in the human genome encoding $\sim 340$ distinct mature miRNAs, many of which are tissuespecific or temporally regulated in their expression (Landgraf 
et al. 2007). However, their biological functions and molecular targets remain largely undefined and experimentally untested. Deletions or mutations in miRNA genes, as well as aberrant expression of oncogenic or tumor-suppressive miRNAs, are common in human cancers (Calin and Croce 2006; Wang et al. 2008), but the causes for their aberrant expression are poorly understood. Although many human viruses produce their own viral miRNAs in the course of virus infection (Pfeffer et al. 2004, 2005; Cai et al. 2005; Samols et al. 2005; Tang et al. 2008; Umbach et al. 2008), there is no report on viral proteins in regulation of cellular miRNA expression.

Recently, miR-34a was identified as a direct transcriptional target of cellular transcription factor p53 (Chang et al. 2007; He et al. 2007; Raver-Shapira et al. 2007). This transactivation of miR-34a expression is triggered by the binding of p53 to a consensus p53 binding site identified in the miR-34a promoter region. Since HPV E6 oncoprotein destabilizes p53 during virus infection, one may assume a down-regulation of miR-34a expression in most cervical cancer tissues with oncogenic HPV infection. However, a direct correlation between down-regulation of miR-34a expression and p53 degradation by HPV oncoprotein E6 in cervical cancer has not been reported. In this study, we provide direct evidence that papillomaviral oncoprotein E6 expressed from HPV16 and HPV18 inhibits the expression of tumor-suppressive miR-34a by destabilization of p53, resulting in cell proliferation.

\section{RESULTS}

\section{Reduction of miR-34a expression in cervical cancer and cervical cancer-derived cell lines}

Our recent study demonstrated that cervical cancer exhibits aberrant expression of several oncogenic and tumorsuppressive miRNAs (Wang et al. 2008). To investigate whether oncogenic HPV infection could alter the expression of certain members of the miRNA family, we examined three pairs of age-matched normal cervix and cervical cancer tissues for the expression of tumor-suppressive miR$34 \mathrm{a}$ by Northern blotting. A profound reduction of miR$34 \mathrm{a}$, which appeared as three separate bands differing by 1 nt and in the sizes of 22-24 nt, was detected in all three cervical cancer tissues, each with a high-risk HPV infection (Fig. 1A,B; Munoz et al. 2003). The heterogeneity of miR$34 \mathrm{a}$ in normal cervix and cervical cancer tissues was probably due to wobble digestion of the pre-miRNA by dicer as recently reported (Landgraf et al. 2007; Wang et al. 2008). The observed reduction of miR-34a in cervical cancer was further confirmed by another method, miRNA ligation assay (Maroney et al. 2007) from a pair of commercially obtained RNA samples derived from normal cervix and cervical cancer tissues (Fig. 1C, lanes 2,3). Consistent with this finding, a remarkable reduction of

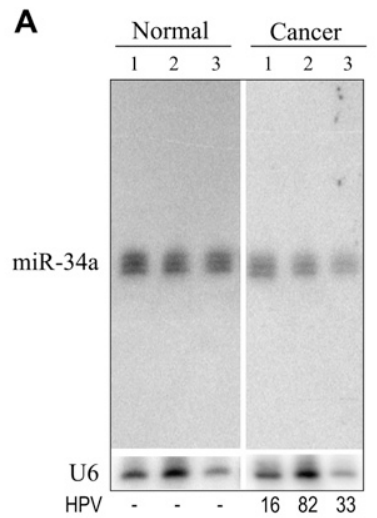

B

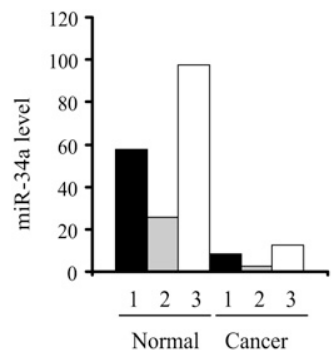

C

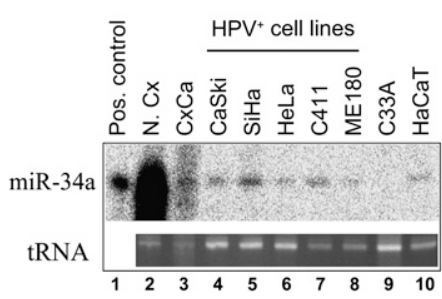

D

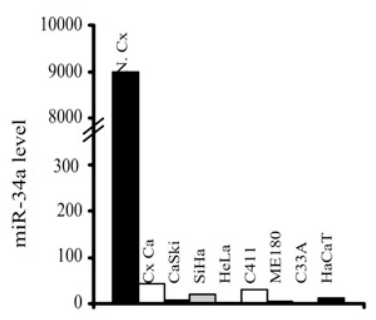

FIGURE 1. Reduction of miR-34a in cervical cancer tissues and cervical cancer-derived cell lines. (A) Cervical cancer tissues express a reduced level of miR-34a. Three age-matched pairs of normal cervix and cervical cancer tissues, each positive for a single genotype (HPV16, 82, or 33), were compared for miR-34a expression by Northern blotting. $(B)$ Bar graph showing relative levels of miR-34a in $A$ after being normalized to U6 snRNA for sample loading. (C) A substantial reduction of miR-34a occurs in cervical cancer-derived cell lines or in human keratinocyte line $\mathrm{HaCaT}$ cells with a mutant p53. (Top panel) Total RNAs from individual cell lines were examined by miRNA ligation analyses. Paired total RNAs from normal cervix $(\mathrm{N}$ $\mathrm{Cx})$, cervical cancer $(\mathrm{CxCa})$ obtained from Ambion and a miRNApositive (Pos.) control from USB were used as controls for this analysis. $(D)$ Bar graph showing relative levels of miR-34a in each sample in $C$ after being normalized to tRNA (bottom in $C$ ) for sample loading.

miR-34a was found in all cervical cancer-derived cell lines containing integrated oncogenic HPV DNA (Fig. 1C, lanes 4-8) and an HPV-negative human keratinocyte line $\mathrm{HaCaT}$ (Fig. 1C, lane 10). There was no miR-34a production in an HPV-negative cervical cancer cell line C33A (Fig. 1C, lane 9). Both HaCaT and C33A cells contain a mutant p53 (Crook et al. 1991; Lehman et al. 1993).

\section{High-risk HPV infection reduces miR-34a expression in host cells}

To determine whether HPV infection causes a reduction of miR-34a prior to cancer development, human primary keratinocytes HVK from adult vaginal tissues or HFK from newborn foreskins were immortalized with oncogenic HPV16 or HPV18 genomic DNA and then grown as organotypic raft cultures on dermal equivalents consisting 
of collagen with embedded fibroblasts. Total RNA isolated from the raft cultures derived from control keratinocytes or HPV-immortalized keratinocytes was examined by Northern blot hybridization. A prominent reduction of miR-34a expression was observed in the raft cultures of the cells immortalized with HPV16 or HPV18 (Fig. 2). HVK, which produces much more miR-34a than HFK, appeared to be more sensitive than HFK for the reduction of miR-34a by high-risk HPV16 and HPV18 infection (Fig. 2A,B). Since cell immortalization by high-risk HPVs is a function of viral oncoproteins E6 and E7 (Munger et al. 2004), these data suggest a possible role of viral oncoproteins in the reduction of miR-34a expression.

We next examined the expression of miR-34a in the raft cultures prepared from HFKs containing HPV18 genomic plasmids without prior immortalization. In this approach, HFK from newborn foreskins was transfected with HPV18 genomic plasmids using Cre-mediated recombination and then put on raft culture for sample collection at days 8,12 , and 16. As shown in Figure 3A, HPV18-infected HFK raft

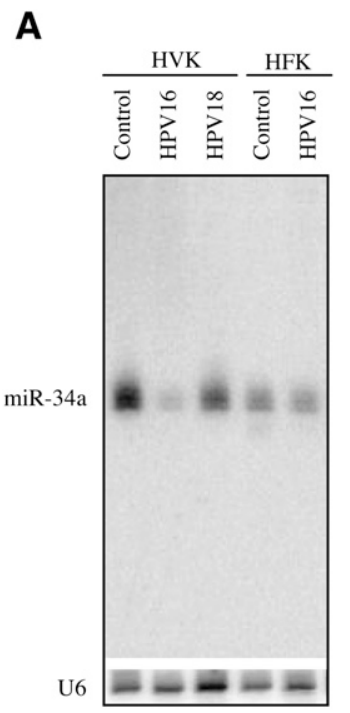

B

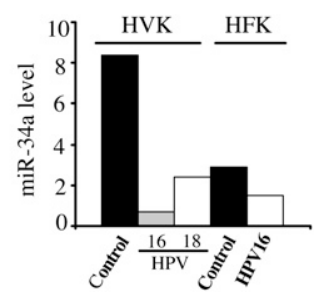

FIGURE 2. Reduction of miR-34a expression in oncogenic HPVimmortalized keratinocytes. (A) Down-regulation of miR-34a in raft cultures derived from HVK or HFK immortalized in vitro by HPV16 or HPV18. Total RNA from each raft culture harvested on day 10 was examined by Northern blotting. (B) Bar graph showing relative miR34a levels in $A$ after being normalized to U6 snRNA for sample loading. cultures, when compared to noninfected ones, grew much faster with a thicker keratinocyte layer at all time points due to HPV18 infection-increased HFK proliferation and led to production of infectious viruses at day 12 and day 16 as indicated by the expression of the major viral capsid protein L1. Relative to control cultures, a notable reduction of miR34a in 8-d-old HPV18-containing raft cultures prior to L1 expression could be observed despite RNA overloading as assessed by its U6 level (Fig. 3B, lane 4). After quantification and normalization to U6 loading, a greater than twofold reduction of miR-34a levels was obtained in the 8-d-old rafts with HPV18 infection (Fig. 3C). These results further imply that viral early proteins are directly involved in the downregulation of miR-34a expression.

\section{A functional p53 is important in the expression of miR-34a in cancer cells, but may be not fully responsible for miR-34a expression in the late stage raft cultures with acute HPV18 infection}

As the expression of miR-34a is transactivated by p53 binding to a perfect p53 binding site in the miR-34a regulatory region (Chang et al. 2007; He et al. 2007; Raver-Shapira et al. 2007), we wish to investigate whether cellular p53 is directly involved in the expression of miR$34 \mathrm{a}$ in cervical cancer and cervical cancer-derived cell lines. The HPV-negative cervical cancer cell line, C33A, was chosen for the study because C33A is expressing a mutant form of p53 (Scheffner et al. 1991) and consequently no detectable miR-34a in a miRNA ligation assay (Fig. 1C), which is in contrast to HaCaT cells, an HPV-negative keratinocyte line. Although also expressing a mutant form of p53 (Lehman et al. 1993), the HaCaT cells do express miR-34a at a substantially reduced level (Fig. 1C). As shown in Figure 4A, both C33A and HPV16 ${ }^{+}$CaSki express a similar amount of miR-16 in Northern blot analyses, but C33A expresses no detectable miR-34a by Northern blotting (Fig. 4A, left panel). However, when wild-type p53 was ectopically expressed for $24 \mathrm{~h}$ in C33A cells by transient transfection, a substantial induction of miR-34a expression became prominent (Fig. 4A, right panel), indicating that the reduced indeed is related directly to destabilized or dysfunctional p53 in cervical cancer cells.

Although miR-34a expression can be transactivated by p53 in cervical cancer cells, an increased expression of miR34a was found not fully associated with cellular p53 level in the late stage of HFK raft cultures with HPV18 infection. As shown in Figure 4B, a decreased expression of miR-34a was associated with a decreased level of p53 in the early stage (day 8) of HFK raft cultures with HPV18 infection. However, relative to the control raft cultures, miR-34a expression was restored in day 12 and day 16 HPV18 raft cultures (Fig. 4B) on or after capsid protein synthesis (Fig. $3 \mathrm{~A}$ ), when there was a high level of viral E7-mediated $\mathrm{p} 21^{\mathrm{cip} 1}$ and a further reduced expression of $\mathrm{p} 53$, implying 
A
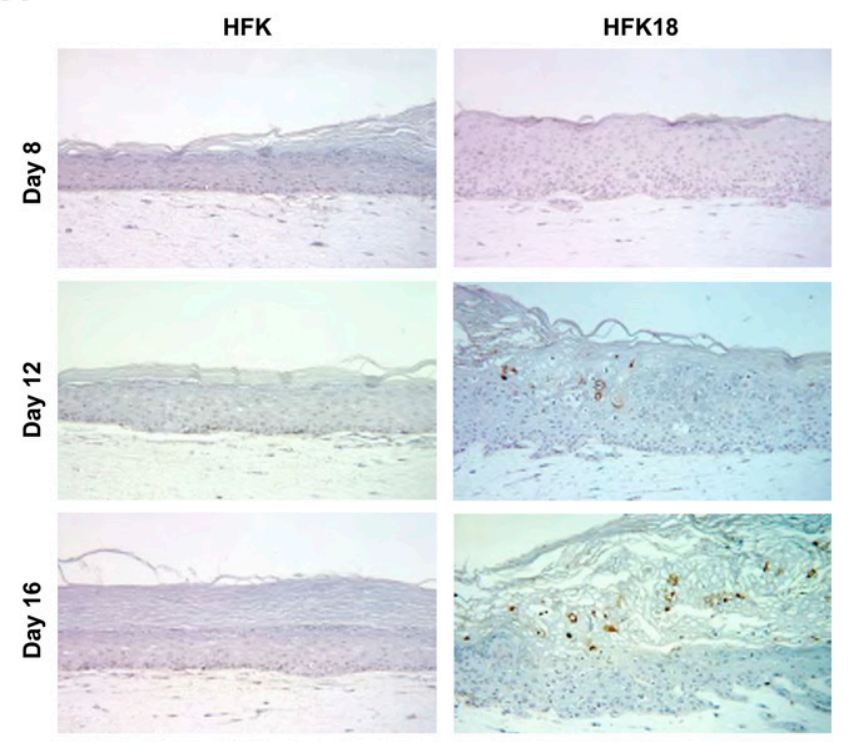

B

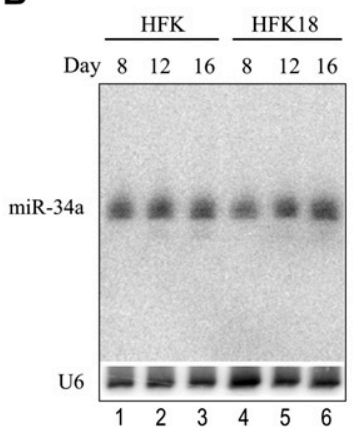

C

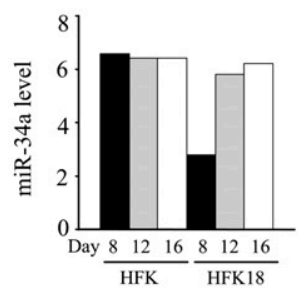

FIGURE 3. HPV early proteins down-regulate the expression of miR34a in HPV18-infected raft cultures. (A) Kinetics of the production of HPV18 L1 in HFK raft cultures. L1 was detected by immunohistochemistry (reddish brown) in terminally differentiated keratinocytes and cornified envelopes at 12-d-old and 16-d-old HPV18-containing HFK raft cultures. (B) Reduction of miR-34a expression in raft cultures of HPV18 DNA-containing HFKs (HFK18) without immortalization on day 8 , but not on days 12 and 16. Total RNAs from raft cultures of different ages were examined by Northern blotting. $(C)$ Bar graph showing relative miR-34a levels in $B$ after being normalized to U6 for sample loading.

the presence of a p53-independent pathway in the expression of miR-34a in this system.

\section{Expression of high-risk HPV oncoprotein E6 reduces miR-34a expression by destabilizing p53}

Since HPV E6 and E7 are two major viral early proteins produced in the early phase of viral infection and are expressed at elevated levels in cervical cancer and their derived cell lines (Munger et al. 2004; Tang et al. 2006b), we next investigated viral E6 expression in correlation with p53 and miR-34a production in HPV1 $8^{+}$HeLa cells and

HPV16 ${ }^{+}$CaSki cells that express the wild-type p53. Through this study, we wish to provide a direct connection of viral E6 oncoprotein to p53 and miR-34a circuit in HPV infection. As shown in Figure 5, knocking down the expression of HPV18 E6 by an HPV18 E6-specific siRNA (Tang et al. 2006b) in HeLa cells stabilized p53 and induced the expression of $\mathrm{p} 21^{\mathrm{cip} 1}$, a downstream target of $\mathrm{p} 53$ transcriptional activation (Fig. 5A,B). As expected, stabilization of p53 in HeLa cells by knocking down HPV18 E6 highly up-regulated miR-34a expression (Fig. 5C,D). Consistent with this observation, knocking down the expression of HPV16 E6 in CaSki cells by an HPV16 E6-specific siRNA also stabilized p53 (Tang et al. 2006b) and up-regulated the expression of miR-34a (Fig. 5E-G).

These observations were further verified in HFKs acutely transduced with HPV18 E6, E7, E6E7, or an empty control

A

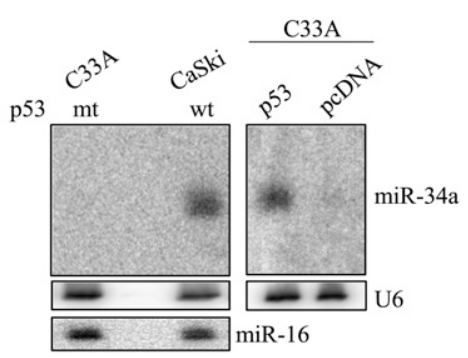

B

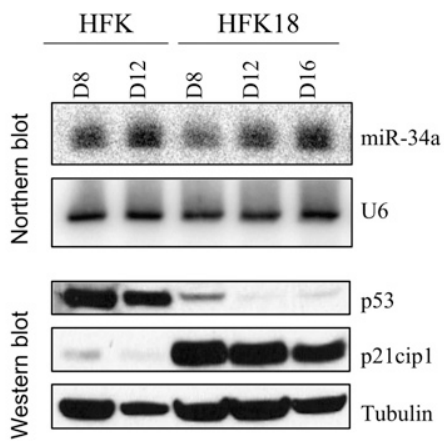

FIGURE 4. Role of wild-type p53 in activation of miR-34a expression from C33A cells and HFK raft cultures with HPV18 infection. (A) Overexpression of wild-type p53 activates miR-34a expression from C33A, an HPV-negative cervical cancer cell line containing a mutant (mt) form of p53. (Left panel) Shows no detectable expression of miR$34 \mathrm{a}$, but miR-16 in C33A cells in comparison with CaSki (HPV16 $\left.{ }^{+}\right)$ cells containing a wild-type (wt) p53 with detectable expression of both miR-34a and miR-16 by Northern blot analyses. (Right panel) Shows miR-34a expression in C33A cells transactivated by ectopic expression of wild-type p53 at $24 \mathrm{~h}$ after transfection. (B) Destabilization of p53 down-regulates the expression of miR-34a in the early, but not in the late HFK raft cultures with HPV18 infection. Raft cultures of HFKs containing HPV18 were harvested on day (D) 8, 12, and 16 and were analyzed for miR-34a expression by Northern blotting and for $\mathrm{p} 53$ and $\mathrm{p} 21^{\mathrm{cip} 1}$ production by Western blotting. $(A, B)$ U6 in each sample served as RNA sample loading in Northern blots. (B) Tubulin in each sample served as protein sample loading in Western blots. 
A

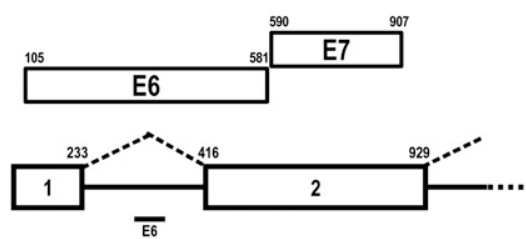

B

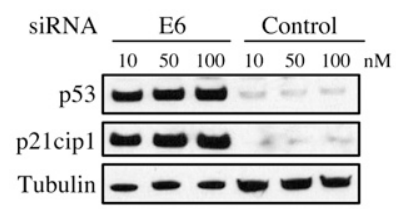

E

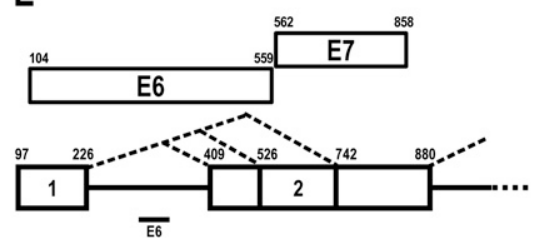

$\mathbf{F}$

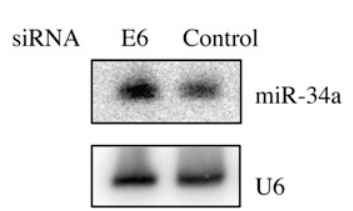

C

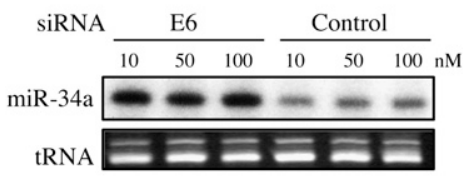

D

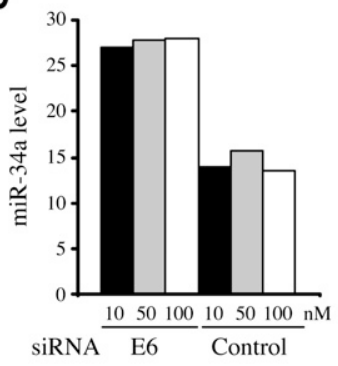

G

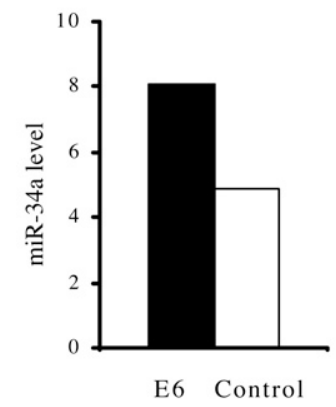

FIGURE 5. Down-regulation of miR-34a by HPV oncoprotein E6 in cervical cancer-derived cell lines. (A) Strategy to silence E6 oncogene expression using an E6 intron-specific siRNA based on splicing of the bicistronic HPV18 E6E7 RNAs (Tang et al. 2006b). (B) Stabilization of p53 and activation of p $21^{\text {cip } 1}$ in HPV18 E6 siRNA-treated HeLa cells. Cell samples at $48 \mathrm{~h}$ after siRNA transfection were examined by Western blotting with tubulin as a loading control. $(C)$ Knocking down E6 expression by an E6-specific siRNA up-regulates the expression of miR-34a in HeLa cells. Total cell RNA $48 \mathrm{~h}$ after an E6-specific siRNA (Tang et al. 2006b) transfection was examined by miRNA ligation analyses (Maroney et al. 2007). (D) Bar graph showing relative miR-34a levels detected in $C$ after being normalized to tRNA for sample loading. $(E)$ Diagram of siRNA targeting to HPV16 E6 (Tang et al. 2006a,b). (F) Knocking down the expression of HPV16 E6 by an E6-specific siRNA promotes the expression of miR-34a in CaSki cells by Northern blotting. $(G)$ Bar graph showing relative miR-34a levels after being normalized to U6 snRNA for sample loading.

retrovirus (Cheng et al. 1995; Banerjee et al. 2005). When HFKs acutely transduced with HPV18 E6 or E7 retrovirus, only the expression of E7 in HFK rafts induced $S$ phase reentry in differentiated keratinocytes (Fig. 6A) and stabilization of $\mathrm{p} 21^{\mathrm{cip} 1}$ (Fig. 6B, top panels), as reported from previous studies (Park et al. 2000; Noya et al. 2001). As predicted, a substantial down-regulation of miR-34a expression was evident only in the E6- or E6E7-expressing raft cultures, but not in E7-expressing raft cultures, relative to cultures infected with vector-only retrovirus (Fig. 6B, lower panels; Fig. 6C). This result correlated with E6 destabilization of p53 (Fig. 6B, top panels), but not with E7-induced
S-phase reentry in differentiated HFKs (Fig. 6A), nor its stabilization of $\mathrm{p} 21^{\text {cip } 1}$ (Fig. 6B, top panels). Collectively, these data indicate that the viral oncoprotein E6 is responsible for the observed downregulation of $\mathrm{miR}-34 \mathrm{a}$ expression in oncogenic HPV-infected cells.

\section{Down-regulation of miR-34a expression in HPV-infected cells by viral E6 promotes cell proliferation}

To determine whether the E6-mediated down-regulation of miR-34a expression is important for the development of cervical cancer, we first demonstrated that the majority of miR-34a in HeLa cells treated with an E6-specific siRNA (Tang et al. 2006b), which stabilized p53 and up-regulated miR-34a (Fig. $5 A-D)$, was found in $G_{0} / G_{1}$-phase cells upon cell sorting. There was a much higher miR-34a ratio (5.5-fold) of $\mathrm{G}_{0} /$ $G_{1}$ versus $S / G_{2} / M$ in E6 siRNA-treated cells than that in control siRNA-treated cells (Fig. 7A,B), consistent with p53 nuclear retention and its highest DNA binding and transactivation activity at the cell $G_{1} / S$ transition (Fogal et al. 2005). We next examined ectopic expression of miR-34a on HeLa cell growth. Because E7 destabilizes hypophosphorylated $\mathrm{pRb}$ in cervical cancer cells, E7-expressing cells lack an efficient checkpoint control in the $G_{1}$ phase of the cell cycle and resist $G_{1}$ growth arrest (Slebos et al. 1994; Jones and Munger 1997). Consistent with this, the ectopic expression of miR-34a in HeLa cells had no effect on $G_{1}$ phase, but led to a moderate cell cycle arrest at the $S$ and $\mathrm{G}_{2} / \mathrm{M}$ phases and apoptosis (Fig. 8A,B).

More importantly, there was a substantial growth retardation in HeLa cells with the ectopic expression of miR-34a (Fig. 8C,D). This suppressive effect on the cell growth was not an immediate cell response; rather, it took a few days to become prominent after two consecutive miR-34a transfections at an interval of $48 \mathrm{~h}$ (Fig. 8C). We infer from these results that cervical cancer cells with low miR-34a expression levels have a growth advantage. Moreover, these effects appear to be independent of the status of $\mathrm{p} 53$ and pRb, as in HPV-negative HCT116 cells, a cell line derived from colon cancer that contains wild-type p53 and increased pRb (Yamamoto et al. 1999) and thus has a functional $G_{1}$ checkpoint, the 
A

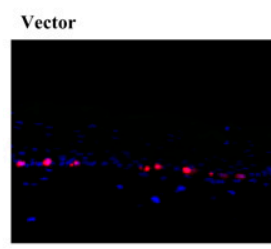

HPV18 URR-E6

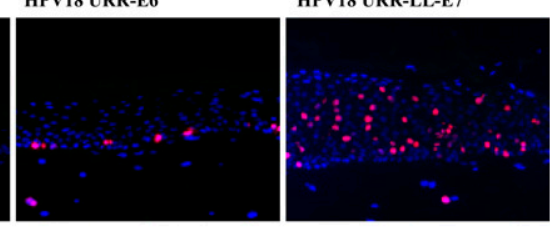

BrdU DAPI

B

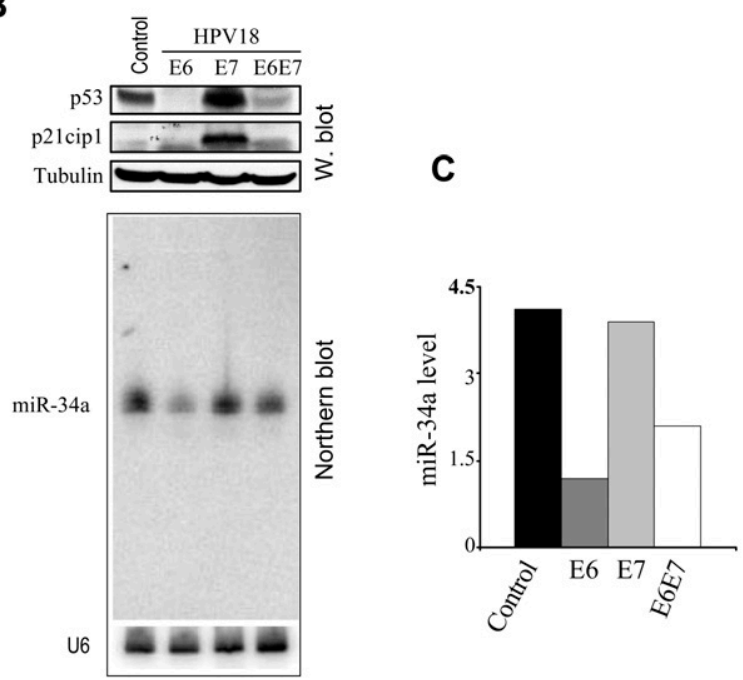

FIGURE 6. Down-regulation of miR-34a expression by HPV18 E6 in HFK raft cultures. (A) S-phase re-entry by differentiated keratinocytes in raft cultures of HFKs transduced with HPV18 E6 or E7 retroviruses. BrdU incorporation was used to show E7-mediated S-phase re-entry. (B) Destabilization of p53 and reduction of miR-34a expression in raft cultures of HFKs acutely transduced with E6 or E6E7, but not by E7, retroviruses. Raft cultures with or without the corresponding retrovirus infection were harvested on day 10 for detection of p53 and p21 by (upper panel) Western (W) blotting or for total RNA preparation and (lower panel) Northern blotting. Tubulin served as protein sample loading in Western blotting. $(C)$ Bar graph showing relative miR-34a levels detected by Northern blotting in $B$ after being normalized to U6 for sample loading.

ectopic expression of miR-34a mediated a moderate cell cycle arrest at $G_{1}$ and caused cell apoptosis and growth retardation (data not shown) in a dose-dependent manner. Similar to HeLa cell growth inhibition, this suppressive effect on HCT116 cell growth by miR-34a was found not to be an immediate cell response.

\section{DISCUSSION}

Although almost all human cancers examined to date display a certain level of aberrant miRNA expression or have mutant forms of miRNA, we know very little about their role in cancer or the cause leading to the aberrant expression. So far, there has been no report whether virus infection could regulate the expression of cellular miRNAs. In this study, we have demonstrated for the first time that
miR-34a is down-regulated in productive, pre-malignant HPV infections, cervical cancer tissues, and cervical cancer cells (Figs. 1-3). This down-regulation can be attributed to the high-risk HPV E6 oncoprotein (Figs. 5,6), which mediates degradation of $\mathrm{p} 53$, a known regulator of miR34a transcription (Chang et al. 2007; He et al. 2007; RaverShapira et al. 2007). This is the first compelling evidence to show a viral oncoprotein being involved in regulation of cellular tumor suppressive miRNAs. On the basis of these observations, we have added a new dimension to HPVinitiated carcinogenesis (Fig. 9). Viral oncoprotein E6 destabilizes p53 and consequently down-regulates the expression of tumor-suppressive miR-34a, providing the cells with a growth advantage. This untimely up-regulation of the viral oncoprotein E6, together with viral oncoprotein E7, which degrades $\mathrm{pRb}$, can result in excessive cell proliferation, initiating the neoplastic and oncogenic processes. As lowrisk HPV E6 does not degrade p53 (Tao et al. 2003), we presume that the low-risk E6 might have no effect on the expression of miR-34a.

Although miR-34a expression can be transactivated by p53 in this study and in several reports (Chang et al. 2007; He et al. 2007; Raver-Shapira et al. 2007), the expression of miR-34a might take place in a p53-independent manner under some particular conditions. The finding that miR34 a expression was restored in this report in day 12 and day 16 HPV18 raft cultures on or after capsid protein synthesis,

A

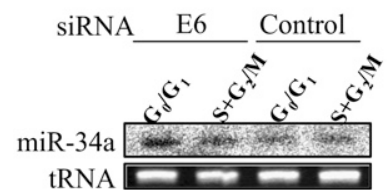

B

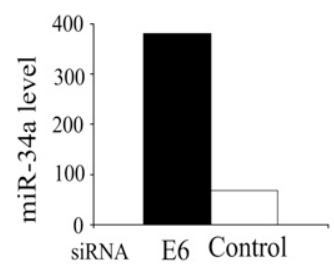

FIGURE 7. Accumulation of miR-34a in $G_{0} / G_{1}$-phase HeLa cells after transfection of E6-specific siRNA. (A) HeLa cells $48 \mathrm{~h}$ following treatment with or without an HPV18 E6-specific siRNA (Tang et al. $2006 \mathrm{~b}$ ) were sorted into $G_{0} / G_{1}$ and $S / G_{2} / M$ subpopulations by flow cytometry, and total RNA from each subpopulation was quantified for miR-34a expression by miRNA ligation analyses. (B) A ratio of miR34a levels in the two subpopulations from each group was calculated after being normalized to tRNA for sample loading. One representative experiment of two is shown. 
A
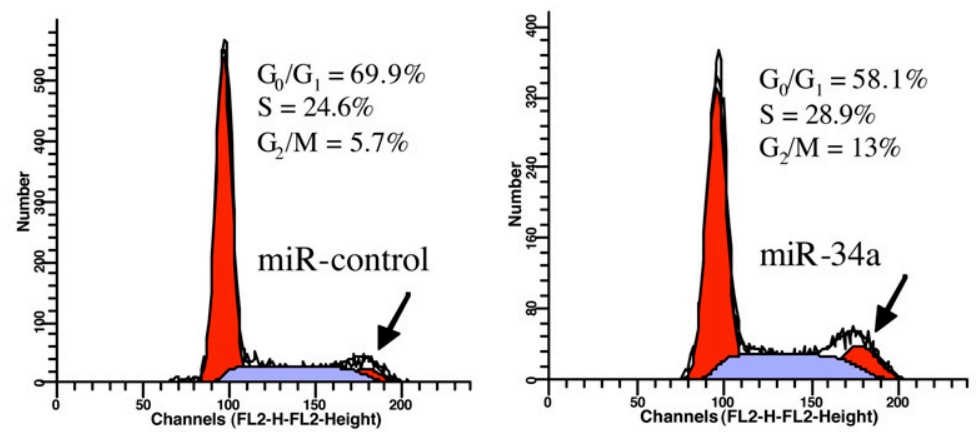

B
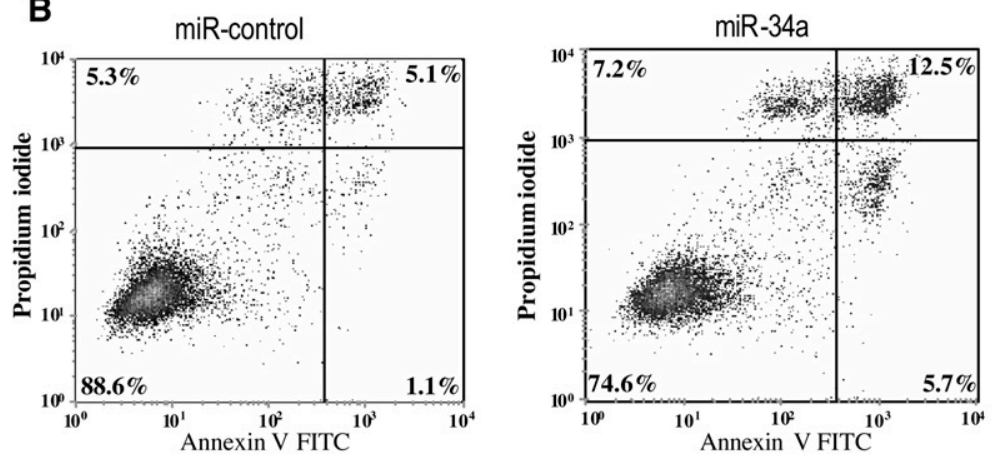

C

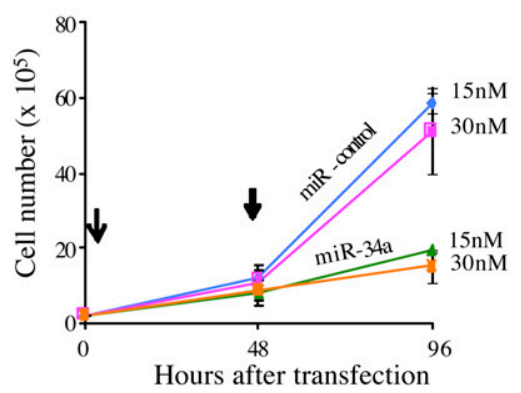

D

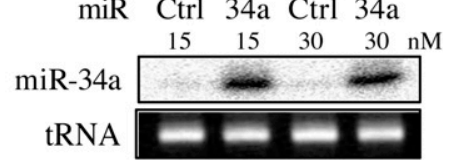

FIGURE 8. Expression of miR-34a in HPV $18^{+}$HeLa cells leads to growth retardation, cell cycle arrest, and apoptosis. $(A, B)$ ectopic expression of miR-34a in HeLa cells leads to $(A)$ cell cycle arrest at $\mathrm{G}_{2}$ and $(B)$ apoptosis. Flow cytometry was conducted with cells transfected twice with miR-34a at an interval of $48 \mathrm{~h}$. (Arrows) Indicate the cell numbers at $\mathrm{G}_{2}$. $(C, D)$ Ectopic expression of miR-34a in HeLa cells suppresses cell growth. $(C)$ HeLa cells received miR-34a transfections (arrows mark transfection time points), and total viable cells were counted. $(D)$ Total cell RNA after miR-34 transfection was analyzed by miRNA ligation analyses and tRNA served as a loading control.

when there was a further reduced expression of p53 and a high level of viral E7-mediated p $21^{\text {cip } 1}$, clearly suggests the presence of a p53-independent pathway in the expression of tumor suppressive miR-34a. We postulate that other transcription factors or chromatin remodeling in the differentiated HFKs must be involved in regulation of miR-34a transcription. A recent study shows that miR34a expression can be inactivated by CpG methylation of its promoter (Lodygin et al. 2008).
The findings of miR-34a substantially accumulated in the $G_{0} / G_{1}$ phase and only a low level in the $S / G_{2} / M$ phase in E6 siRNA-treated HeLa cells suggest an elevated expression or stability of miR34a in $G_{0} / G_{1}$-phase cells. This elevated steady-state miR-34a level in $\mathrm{G}_{0} / \mathrm{G}_{1^{-}}$ phase cells would contribute to an increased cell population arrested at the $G_{1}$ phase when a functional $G_{1}$ checkpoint is present in HPV-negative HCT116 cells (data not shown) or other cell lines ( $\mathrm{He}$ et al. 2007; Tarasov et al. 2007). As nuclear retention and transactivation functions of Ser315phosphorylated p53 are the highest at the $G_{1} / S$ transition and the Ser315 phosphorylation by increased cyclin A expression in the $S$ phase could decrease p53 nuclear activities by promoting p53 nuclear export (Fogal et al. 2005), the elevated steady-state miR-34a level in $\mathrm{G}_{0} / \mathrm{G}_{1}$ phase cells observed in this study could be simply ascribed to this cell cycle-dependent nuclear retention and activities of Ser315-phosphorylated p53. Cell cycle-dependent changes in miRNA stability have been recently reported in HeLa cells, in which miR-29a and miR30 were found to be constitutively expressed in all cell cycle phases, but miR$29 \mathrm{~b}$ was expressed highly only in mitotic cells (Hwang et al. 2007). Thus, our data together with this report indicate a cell cycle-dependent regulation of miRNA expression and stability in controlling miRNA functions.

MiRNAs exercise large-scale effects on the expression of a variety of genes at the post-transcriptional level, and are estimated to regulate $\sim 30 \%$ of mammalian genes. By prediction and experimental analyses, any given miRNA may have hundreds of gene targets (Brennecke et al. 2005; Farh et al. 2005; Lewis et al. 2005). In this study, we have demonstrated that cells with a reduced level of miR-34a expression have a growth advantage since the ectopic expression of miR34a induces cell growth retardation and a moderate cell cycle arrest and apoptosis. As a moderate cell cycle arrest and apoptosis observed in this study might not fully cause a substantial cell growth retardation in the cells with the ectopic expression of miR-34a, the growth retardation mediated by miR-34a could be ascribed to many other unnoticed effects of miR-34a. For example, miR-34a has 


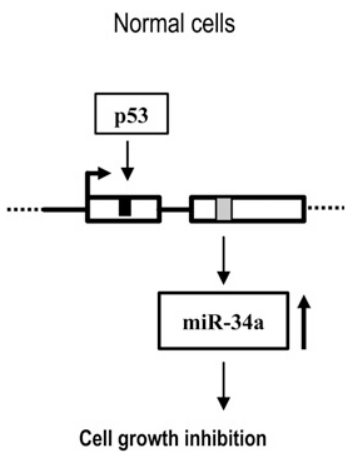

FIGURE 9. A model for miR-34a expression and its role in the development of cervical cancer. (Left) Normal cells express wt p53, which activates the expression of tumor-suppressive miR-34a to control cell proliferation and growth. Viral E6 expression from oncogenic HPVs causes the destabilization of cellular p53 and reduction of tumor-suppressive miR-34a, leading to uncontrolled cell proliferation and development of cancer. (Black box) p53 binding site; (shaded box) miR-34a coding region.

been found to target multiple cell cycle components, including CDK4, cyclin E2, E2F-1, hepatocyte growth factor receptor $\mathrm{MET}$, and $\mathrm{Bcl}-2$ in other studies (Bommer et al. 2007; He et al. 2007; Tazawa et al. 2007; Welch et al. 2007). This multitargeting capacity by a single miRNA on cell cycling machinery may fine-tune a checkpoint for cell cycle progression. Recently, we also found that the ectopic expression of certain tumor-suppressive or oncogenic miRNAs affects cell doubling time (Wang et al. 2008). Thus, an efficient cell growth retardation mediated by miR-34a could result from a collection of many miR-34a-target interactions in spite of the fact that the exact mechanism by which miR34a might function remains to be understood.

In summary, this is the first time that a viral oncoprotein has been shown to regulate cellular noncoding gene expression and the first report of viral regulation of expression of a tumor suppressor miRNA. We have shown that at all stages of pathogenesis induced by the high-risk HPV types, the E6 destabilization of the tumor suppressor p53 down-regulates the tumor-suppressive miR-34a, leading to the elevated expression of cell cycle regulators and cell proliferation. These intimate interplays among viral E6, p53, miR-34a, and E7 place miR-34a in a central role in a well-known viral oncoprotein-tumor suppressor network.

\section{MATERIALS AND METHODS}

\section{Cell lines and human tissues}

HPV16-positive cell lines CaSki and SiHa, HPV18-positive cell lines HeLa and C411, HPV68-positive cell line ME180 (Longuet et al. 1996), HPV-negative cervical cancer cell line C33A, and HPV-negative human keratinocyte line $\mathrm{HaCaT}$ cells (Stanley et al. 1989) were used in this study. All of these cells were grown in Dulbecco's modified Eagle's medium (DMEM) with 10\% FBS at $37^{\circ} \mathrm{C}$ and $5 \% \mathrm{CO}_{2}$. HCT116 cells derived from colon cancer were grown in McCoy's 5A medium with 10\% FBS. Normal cervix and cervical cancer tissues were obtained from women with an age range from 40 to $50 \mathrm{yr}$ old. HPV genotyping was done by sequencing-based techniques as previously described (Zhang et al. 2007). Use of these tissues was approved both by the Washington University Medical Center Human Studies Committee and by the NIH Office of Human Subjects Research. Each tissue was homogenized in an Eppendorf tube in $1 \mathrm{~mL}$ of TRIzol Reagent (Invitrogen) using an electric homogenizer (Omni International) with a separate disposable probe. The isolated RNA was dissolved in RNase-free water and stored at $-70^{\circ} \mathrm{C}$.

\section{Northern blot analysis}

Total RNA (30-40 $\mu \mathrm{g})$ was separated on a $15 \%$ denaturing polyacrylamide gel and transferred onto a GeneScreen Plus Hybridization Transfer Membrane (PerkinElmer) in $0.5 \times$ TBE buffer. The membrane was pre-hybridized with PerfectHyb Plus hybridization buffer (Sigma) for $2 \mathrm{~h}$ and then hybridized with $\left[\gamma-{ }^{32} \mathrm{P}\right]$-labeled miRNA-specific antisense probe overnight at $40^{\circ} \mathrm{C}$. The membrane was washed sequentially in $50 \mathrm{~mL}$ of $2 \times$ SSPE containing $0.5 \%$ SDS, $0.5 \times$ SSPE containing $0.5 \%$ SDS, and $0.2 \times$ SSPE containing $0.1 \%$ SDS for $30 \mathrm{~min}$ each at $40^{\circ} \mathrm{C}$, and then exposed to a PhosphorImager screen. The image was captured using a Molecular Dynamics PhosphorImager Storm 860 and analyzed with ImageQuant software. The same membrane was stripped with $0.1 \times \mathrm{SSPE}, 0.5 \% \mathrm{SDS}$ for $20-30 \mathrm{~min}$ at $90^{\circ} \mathrm{C}$ and equilibrated with hybridization buffer for $2 \mathrm{~h}$ and then hybridized with the U6 snRNA probe. The antisense oligodeoxynucleotide probes were designed based on individual miRNA sequences deposited in miRBase (http://microrna.sanger.ac.uk). An antisense oligodeoxynucleotide (oST197, 5'-AAAATATGGA ACGCTTCACGA-3') was used to detect U6 snRNA from each sample as a loading control.

\section{miRNA ligation assay}

The miRNA ligation assay (Maroney et al. 2007) was performed using the miRtect-IT miRNA Labeling and Detection Kit (USB). In brief, detection oligo (oXHW66, 5'-CGCTTATGACATTC-3') was $5^{\prime}$-end-labeled with $\left[\gamma^{-}{ }^{32} \mathrm{P}\right] \mathrm{ATP}$ and OptiKinase. The miRNA in total RNA and the radiolabeled detection oligodeoxynucleotide were captured with miR-34a-specific bridge oligodeoxynucleotide (oXHW 79, 5'-GAATGTCATAAGCG/ACAACCAGCTAAGACA CTGCCA-3'), and these were then ligated with T4 DNA ligase. The ligated miRNA was separated on a $15 \%$ denaturing polyacrylamide gel and exposed to a PhosphorImager screen for $2.5 \mathrm{~h}$. The image was captured and analyzed as described above. After exposure, the gel was stained for tRNAs from each sample as a loading control with ethidium bromide (Yi et al. 2006). Depending on the designed bridge oligonucleotide, the miRNA ligation assay detects only one isoform of the interested miRNA.

\section{Western blot analysis}

Twenty-five microliters of cell protein lysates were denatured by boiling for $5 \mathrm{~min}$ and separated in a NuPAGE 4\%-12\% Bis-Tris gel (Invitrogen) in $1 \times$ NuPAGE MES SDS running buffer (Invitrogen). After transfer, the nitrocellulose membrane was blocked with 5\% nonfat dry milk in Tris-buffered saline (TBS) (10 mM Tris, $150 \mathrm{mM}$ $\mathrm{NaCl}$ at $\mathrm{pH}$ 7.4) for $1 \mathrm{~h}$ at room temperature. After a brief wash with 
TBS, the membrane was incubated overnight at $4^{\circ} \mathrm{C}$ with primary antibody. The membrane was washed three times with TTBS (TBS with Tween 20 at a final concentration of $0.05 \%$ [ $\mathrm{vol} / \mathrm{vol}]$ ). Horseradish peroxidase-labeled secondary antibody (Sigma) diluted 10,000-fold in TTBS was incubated for $1 \mathrm{~h}$ at room temperature. After thorough washing, the immunoreactive proteins were detected with enhanced chemiluminescence using SuperSignal West Pico Western chemiluminescence substrate (Pierce). The signal was captured on X-ray film. The membrane was stripped and reprobed with another primary antibody. The primary monoclonal antibodies used were anti-p53 (Calbiochem; Ab-6, 1:100), anti-p21cip1 (BD Pharmingen; 6B6, 1:100), and anti- $\beta$-tubulin antibody (BD Pharmingen, 5H1, 1:1000).

\section{Cell transfection}

HeLa cells and HCT116 cells were transfected with 15 or $30 \mathrm{nM}$ miR-34a Pre-miR Precursor (Ambion) or negative nonspecific control Pre-miR Precursor (Ambion) using siPORT NeoFX Transfection Agent (Ambion, Cat \#4511) according to the manufacturer's instructions. After $48 \mathrm{~h}$, the cells were counted and transfected again with each corresponding miRNA with the same dose. After an additional $48 \mathrm{~h}$, the cells were counted, and total RNA was extracted with TRIzol Reagent.

HPV-negative cervical cancer cells C33A at $5 \times 10^{5} / \mathrm{mL}$ in a 6well plate were transfected with $4 \mu \mathrm{g} /$ well of a wild-type p53 expression vector or an empty control vector using Lipofectamine 2000. Total RNA was prepared for Northern blotting $24 \mathrm{~h}$ after transfection.

\section{RNAi interference}

Ten, 50, or $100 \mathrm{nM}$ synthetic double-stranded siRNA 219, which targets the HPV18 E6 coding region in intron 1 (nucleotides 353 to 371 ), or $40 \mathrm{nM}$ synthetic double-stranded siRNA 209, which targets the HPV16 E6 coding region in intron 1 (nucleotides 277 to 298) (Tang et al. 2006b), were transfected into HeLa cells or CaSki cells, respectively, with siPORT NeoFX Transfection Agent (Ambion). Cells were seeded in triplicate in 6-well plates. Fortyeight hours post-transfection, total cell protein lysates were prepared by the addition of $2 \times$ sodium dodecyl sulfate (SDS) loading buffer, and total RNA was extracted with TRIzol Reagent (Invitrogen).

\section{Flow cytometry}

Apoptosis in HeLa or HCT116 cells was analyzed using Annexin V-FITC Apoptosis Detection Kit II (BD Pharmingen). Cells were trypsinized, washed twice with cold PBS, and then resuspended in $1 \times$ binding buffer at $1 \times 10^{6}$ cells $/ \mathrm{mL}$. Five microliters of annexin $\mathrm{V}$-FITC and $5 \mu \mathrm{L}$ of propidium iodide (PI) were added to $100 \mu \mathrm{L}$ of cells $\left(1 \times 10^{5}\right.$ cells $)$ in a 5-mL culture tube and incubated for $15 \mathrm{~min}$ at room temperature in the dark. After incubation, $400 \mu \mathrm{L}$ of $1 \times$ binding buffer was added to each tube, and the samples were analyzed by flow cytometry within $1 \mathrm{~h}$. For cell cycle analysis, the cells in suspension were stained with propidium iodide and analyzed by flow cytometry. For cell sorting and miR detection, HeLa cells at $2.3 \times 10^{5} / \mathrm{mL}$ were transfected with $10 \mathrm{nM}$ siRNA 219 (HPV18 E6 siRNA) (Tang et al. 2006b) with siPORT NeoFX Transfection Agent (Ambion). After $48 \mathrm{~h}$ of incubation, cells were trypsinized, resuspended in serum-free medium at $3 \times 10^{6}$ cells $/ \mathrm{mL}$, and stained with $15 \mu \mathrm{g} / \mathrm{mL}$ Hoechst 33342 (Invitrogen) for $1.5 \mathrm{~h}$ at $37^{\circ} \mathrm{C}$. After pelleting by a brief centrifugation, the cells were resuspended in $500 \mu \mathrm{L}$ of serum-free medium and subjected to cell sorting by flow cytometry. Total RNA from the sorted cells was extracted with TRIzol Reagent for miRNA detection.

\section{Primary human keratinocytes, retrovirus infection, and organotypic cultures}

Primary human foreskin keratinocytes (HFKs) and human vaginal keratinocytes (HVKs) were cultured in KSFM (Invitrogen) as described previously (Dollard et al. 1992; Meyers et al. 1992) and immortalized by HPV16 or HPV18 genomic DNA. Raft cultures were prepared as described (McLaughlin-Drubin and Meyers 2005). The method to generate HPV18 genomic plasmids using Cre-mediated recombination in transfected HFKs, without immortalization as well as the production of infectious HPV18 progeny viruses in raft cultures, has been described elsewhere (Wang et al. 2009).

The empty retroviral vector pLC and the pLJ HPV18 URR E6/ E7 have been described previously (Cheng et al. 1995). The viral oncogenes are under the control of the homologous $1-\mathrm{kb}$ contiguous upstream regulatory region (URR) containing transcription enhancers and the E6 promoter. The pLC-18URR-LLE7 has a URR in control of the expression of the HPV18 E7 gene with a long 5' UTR derived from a truncated E6 gene (Genovese et al. 2008). The pLJ-18URR-E6 was derived from pLJ-18URR-E6E7 by removing the HPV18 sequences downstream from E6 between flanking Nsil sites. Amphotropic recombinant retroviruses were prepared from GP+envAM12 (ATCC). Infected HFKs were selected with $250 \mu \mathrm{g} / \mathrm{mL}$ G418 for $2 \mathrm{~d}$ and then develop into organotypic cultures as previously described (Wilson et al. 1992; Cheng et al. 1995; Banerjee et al. 2005). The medium was supplemented with $50 \mu \mathrm{g} / \mathrm{mL}$ BrdU for $12 \mathrm{~h}$ immediately before harvest on day 10 to mark cells in S phase. The raft cultures were collected free from collagen (no fibroblasts) at specified time points and frozen in dry ice for total RNA and/or protein preparation or were formalin-fixed and paraffin-embedded for in situ analysis.

\section{Immunohistochemistry and microscopy}

Four-micrometer sections of raft culture were deparaffinized and stained with hematoxylin and eosin or subjected to immunohistochemistry. BrdU was detected with the mouse anti-BrdU antibody (1:100 dilution; Calbiochem) followed by Alexa 555conjugated goat anti-mouse antibody (1:200 dilution; Invitrogen/ Molecular Probes). Images were acquired with an Olympus AX70 fluorescence microscope with Speicher filters (Chroma) and a Carl Zeiss Axiocam HR digital camera. The HPV18 L1 major capsid protein was detected with a monoclonal primary antibody $\mathrm{K} 1 \mathrm{H} 8$ (1:100; DakoCytomation Inc.) and reacted with Concentrated Detection System (BioGenex) and DAB kit (Innovex Biosciences). The sections were counterstained with hematoxylin and mounted with Permount. Images were captured with an Olympus $\mathrm{BH} 2$ microscope using a SPOT camera (Diagnostic Instruments).

\section{ACKNOWLEDGMENTS}

We thank John Brady at the National Cancer Institute for the p53 expression vector. This work was supported by the Intramural 
Research Program of the National Institutes of Health, the National Cancer Institute, and the Center for Cancer Research and National Heart, Lung, and Blood Institute. This work also was supported partially by grants from the U.S. National Institutes of Health: Grant Nos. CA095713 (to J.S.R.), AI057988 (to C.M.), and CA083679 (to L.T.C.).

Received November 1, 2008; accepted December 22, 2008.

\section{REFERENCES}

Banerjee, N.S., Chow, L.T., and Broker, T.R. 2005. Retrovirusmediated gene transfer to analyze HPV gene regulation and protein functions in organotypic "raft" cultures. Methods Mol. Med. 119: 187-202.

Bommer, G.T., Gerin, I., Feng, Y., Kaczorowski, A.J., Kuick, R., Love, R.E., Zhai, Y., Giordano, T.J., Qin, Z.S., Moore, B.B., et al. 2007. p53-mediated activation of miRNA34 candidate tumorsuppressor genes. Curr. Biol. 17: 1298-1307.

Brennecke, J., Stark, A., Russell, R.B., and Cohen, S.M. 2005. Principles of microRNA-target recognition. PLoS Biol. 3: e85. doi: 10.1371/journal.pbio.0030085.

Cai, X., Lu, S., Zhang, Z., Gonzalez, C.M., Damania, B., and Cullen, B.R. 2005. Kaposi's sarcoma-associated herpesvirus expresses an array of viral microRNAs in latently infected cells. Proc. Natl. Acad. Sci. 102: 5570-5575.

Calin, G.A. and Croce, C.M. 2006. MicroRNA signatures in human cancers. Nat. Rev. Cancer 6: 857-866.

Chang, T.C., Wentzel, E.A., Kent, O.A., Ramachandran, K., Mullendore, M., Lee, K.H., Feldmann, G., Yamakuchi, M., Ferlito, M., Lowenstein, C.J., et al. 2007. Transactivation of miR$34 \mathrm{a}$ by p53 broadly influences gene expression and promotes apoptosis. Mol. Cell 26: 745-752.

Chellappan, S., Kraus, V.B., Kroger, B., Munger, K., Howley, P.M., Phelps, W.C., and Nevins, J.R. 1992. Adenovirus E1A, simian virus 40 tumor antigen, and human papillomavirus E7 protein share the capacity to disrupt the interaction between transcription factor E2F and the retinoblastoma gene product. Proc. Natl. Acad. Sci. 89: 4549-4553.

Cheng, S., Schmidt-Grimminger, D.C., Murant, T., Broker, T.R., and Chow, L.T. 1995. Differentiation-dependent up-regulation of the human papillomavirus E7 gene reactivates cellular DNA replication in suprabasal differentiated keratinocytes. Genes \& Dev. 9: 2335-2349.

Cobrinik, D. 2005. Pocket proteins and cell cycle control. Oncogene 24: 2796-2809.

Crook, T., Wrede, D., and Vousden, K.H. 1991. p53 point mutation in HPV negative human cervical carcinoma cell lines. Oncogene 6: 873-875.

Dollard, S.C., Wilson, J.L., Demeter, L.M., Bonnez, W., Reichman, R.C., Broker, T.R., and Chow, L.T. 1992. Production of human papillomavirus and modulation of the infectious program in epithelial raft cultures. Genes \& Dev. 6: 1131-1142.

Farh, K.K., Grimson, A., Jan, C., Lewis, B.P., Johnston, W.K., Lim, L.P., Burge, C.B., and Bartel, D.P. 2005. The widespread impact of mammalian microRNAs on mRNA repression and evolution. Science 310: 1817-1821.

Fogal, V., Hsieh, J.K., Royer, C., Zhong, S., and Lu, X. 2005. Cell cycle-dependent nuclear retention of $\mathrm{p} 53$ by E2F1 requires phosphorylation of p53 at Ser315. EMBO J. 24: 2768-2782.

Genovese, N.J., Banerjee, N.S., Broker, T.R., and Chow, L.T. 2008. Casein kinase II motif-dependent phosphorylation of the human papillomavirus E7 protein promotes p130 degradation and S-phase induction in differentiated human keratinocytes. J. Virol. 82: $4862-4873$

Gonzalez, S.L., Stremlau, M., He, X., Basile, J.R., and Munger, K. 2001. Degradation of the retinoblastoma tumor suppressor by the human papillomavirus type $16 \mathrm{E} 7$ oncoprotein is important for functional inactivation and is separable from proteasomal degradation of E7. J. Virol. 75: 7583-7591.

Grimson, A., Farh, K.K., Johnston, W.K., Garrett-Engele, P., Lim, L.P., and Bartel, D.P. 2007. MicroRNA targeting specificity in mammals: Determinants beyond seed pairing. Mol. Cell 27: 91105.

Halazonetis, T.D., Gorgoulis, V.G., and Bartek, J. 2008. An oncogeneinduced DNA damage model for cancer development. Science 319: 1352-1355.

He, L., He, X., Lim, L.P., de Stanchina, E., Xuan, Z., Liang, Y., Xue, W., Zender, L., Magnus, J., Ridzon, D., et al. 2007. A microRNA component of the p53 tumour suppressor network. Nature 447: 1130-1134.

Hwang, H.W., Wentzel, E.A., and Mendell, J.T. 2007. A hexanucleotide element directs microRNA nuclear import. Science 315: 97-100.

Jones, D.L. and Munger, K. 1997. Analysis of the p53-mediated $G_{1}$ growth arrest pathway in cells expressing the human papillomavirus type 16 E7 oncoprotein. J. Virol. 71: 2905-2912.

Landgraf, P., Rusu, M., Sheridan, R., Sewer, A., Iovino, N., Aravin, A., Pfeffer, S., Rice, A., Kamphorst, A.O., Landthaler, M., et al. 2007. A mammalian microRNA expression atlas based on small RNA library sequencing. Cell 129: 1401-1414.

Lehman, T.A., Modali, R., Boukamp, P., Stanek, J., Bennett, W.P., Welsh, J.A., Metcalf, R.A., Stampfer, M.R., Fusenig, N., Rogan, E.M., et al. 1993. p53 mutations in human immortalized epithelial cell lines. Carcinogenesis 14: 833-839.

Lewis, B.P., Burge, C.B., and Bartel, D.P. 2005. Conserved seed pairing, often flanked by adenosines, indicates that thousands of human genes are microRNA targets. Cell 120: 15-20.

Lodygin, D., Tarasov, V., Epanchintsev, A., Berking, C., Knyazeva, T., Korner, H., Knyazev, P., Diebold, J., and Hermeking, H. 2008. Inactivation of miR-34a by aberrant $\mathrm{CpG}$ methylation in multiple types of cancer. Cell Cycle 7: 2591-2600.

Longuet, M., Beaudenon, S., and Orth, G. 1996. Two novel genital human papillomavirus (HPV) types, HPV68 and HPV70, related to the potentially oncogenic HPV39. J. Clin. Microbiol. 34: 738744.

Lytle, J.R., Yario, T.A., and Steitz, J.A. 2007. Target mRNAs are repressed as efficiently by microRNA-binding sites in the $5^{\prime}$ UTR as in the 3' UTR. Proc. Natl. Acad. Sci. 104: 9667-9672.

Maroney, P.A., Chamnongpol, S., Souret, F., and Nilsen, T.W. 2007. A rapid, quantitative assay for direct detection of microRNAs and other small RNAs using splinted ligation. RNA 13: 930-936.

McLaughlin-Drubin, M.E. and Meyers, C. 2005. Propagation of infectious, high-risk HPV in organotypic "raft" culture. Methods Mol. Med. 119: 171-186.

Meyers, C., Frattini, M.G., Hudson, J.B., and Laimins, L.A. 1992. Biosynthesis of human papillomavirus from a continuous cell line upon epithelial differentiation. Science 257: 971-973.

Mirza, A., Wu, Q., Wang, L., McClanahan, T., Bishop, W.R., Gheyas, F., Ding, W., Hutchins, B., Hockenberry, T., Kirschmeier, P., et al. 2003. Global transcriptional program of p53 target genes during the process of apoptosis and cell cycle progression. Oncogene 22: 3645-3654.

Munger, K., Baldwin, A., Edwards, K.M., Hayakawa, H., Nguyen, C.L., Owens, M., Grace, M., and Huh, K. 2004. Mechanisms of human papillomavirus-induced oncogenesis. J. Virol. 78: 11451-11460.

Muñoz, N., Bosch, F.X., de Sanjosé, S., Herrero, R., Castellsagué, X., Shah, K.V., Snijders, P.J., and Meijer, C.J.; International Agency for Research on Cancer Multicenter Cervical Cancer Study Group. 2003. Epidemiologic classification of human papillomavirus types associated with cervical cancer. N. Engl. J. Med. 348: 518-527.

Nielsen, C.B., Shomron, N., Sandberg, R., Hornstein, E., Kitzman, J., and Burge, C.B. 2007. Determinants of targeting by endogenous and exogenous microRNAs and siRNAs. RNA 13: 1894-1910.

Noya, F., Chien, W.M., Broker, T.R., and Chow, L.T. 2001. p21 ${ }^{\text {cip } 1}$ degradation in differentiated keratinocytes is abrogated by costabilization with cyclin $\mathrm{E}$ induced by human papillomavirus E7. J. Virol. 75: 6121-6134. 
Park, J.S., Boyer, S., Mitchell, K., Gilfor, D., Birrer, M., Darlington, G., El Deiry, W., Firestone, G.L., Munger, K., Band, V., et al. 2000. Expression of human papilloma virus E7 protein causes apoptosis and inhibits DNA synthesis in primary hepatocytes via increased expression of $\mathrm{p}^{2} 1^{\mathrm{Cip}-1 / \mathrm{WAF} 1 / \mathrm{MDA}}$. J. Biol. Chem. 275: 18-28.

Pfeffer, S., Zavolan, M., Grasser, F.A., Chien, M., Russo, J.J., Ju, J., John, B., Enright, A.J., Marks, D., Sander, C., et al. 2004. Identification of virus-encoded microRNAs. Science 304: 734-736.

Pfeffer, S., Sewer, A., Lagos-Quintana, M., Sheridan, R., Sander, C., Grasser, F.A., van Dyk, L.F., Ho, C.K., Shuman, S., Chien, M., et al. 2005. Identification of microRNAs of the herpesvirus family. Nat. Methods 2: 269-276.

Raver-Shapira, N., Marciano, E., Meiri, E., Spector, Y., Rosenfeld, N., Moskovits, N., Bentwich, Z., and Oren, M. 2007. Transcriptional activation of miR-34a contributes to p53-mediated apoptosis. Mol. Cell 26: 731-743.

Samols, M.A., Hu, J., Skalsky, R.L., and Renne, R. 2005. Cloning and identification of a microRNA cluster within the latency-associated region of Kaposi's sarcoma-associated herpesvirus. J. Virol. 79: 9301-9305.

Scheffner, M., Werness, B.A., Huibregtse, J.M., Levine, A.J., and Howley, P.M. 1990. The E6 oncoprotein encoded by human papillomavirus types 16 and 18 promotes the degradation of p53. Cell 63: 1129-1136.

Scheffner, M., Munger, K., Byrne, J.C., and Howley, P.M. 1991. The state of the p53 and retinoblastoma genes in human cervical carcinoma cell lines. Proc. Natl. Acad. Sci. 88: 5523-5527.

Slebos, R.J., Lee, M.H., Plunkett, B.S., Kessis, T.D., Williams, B.O., Jacks, T., Hedrick, L., Kastan, M.B., and Cho, K.R. 1994. p53dependent $G_{1}$ arrest involves pRB-related proteins and is disrupted by the human papillomavirus 16 E7 oncoprotein. Proc. Natl. Acad. Sci. 91: 5320-5324.

Stanley, M.A., Browne, H.M., Appleby, M., and Minson, A.C. 1989. Properties of a nontumorigenic human cervical keratinocyte cell line. Int. J. Cancer 43: 672-676.

Tang, S., Tao, M., McCoy, J.P., and Zheng, Z.M. 2006a. Short-term induction and long-term suppression of HPV16 oncogene silencing by RNA interference in cervical cancer cells. Oncogene 25: 2094-2104.

Tang, S., Tao, M., McCoy Jr., J.P., and Zheng, Z.M. 2006b. The E7 oncoprotein is translated from spliced $\mathrm{E}^{\star} \mathrm{I}$ transcripts in high-risk human papillomavirus type 16- or type 18-positive cervical cancer cell lines via translation reinitiation. J. Virol. 80: 4249-4263.

Tang, S., Bertke, A.S., Patel, A., Wang, K., Cohen, J.I., and Krause, P.R. 2008. An acutely and latently expressed herpes simplex virus 2 viral microRNA inhibits expression of ICP34.5, a viral neurovirulence factor. Proc. Natl. Acad. Sci. 105: 10931-10936.
Tao, M., Kruhlak, M., Xia, S., Androphy, E., and Zheng, Z.M. 2003. Signals that dictate nuclear localization of human papillomavirus type 16 oncoprotein E6 in living cells. J. Virol. 77: 1323213247.

Tarasov, V., Jung, P., Verdoodt, B., Lodygin, D., Epanchintsev, A., Menssen, A., Meister, G., and Hermeking, H. 2007. Differential regulation of microRNAs by p53 revealed by massively parallel sequencing: miR-34a is a p53 target that induces apoptosis and $\mathrm{G}_{1}$-arrest. Cell Cycle 6: 1586-1593.

Tazawa, H., Tsuchiya, N., Izumiya, M., and Nakagama, H. 2007. Tumor-suppressive miR-34a induces senescence-like growth arrest through modulation of the E2F pathway in human colon cancer cells. Proc. Natl. Acad. Sci. 104: 15472-15477.

Umbach, J.L., Kramer, M.F., Jurak, I., Karnowski, H.W., Coen, D.M., and Cullen, B.R. 2008. MicroRNAs expressed by herpes simplex virus 1 during latent infection regulate viral mRNAs. Nature 454: 780-783.

Vousden, K.H. and Lane, D.P. 2007. p53 in health and disease. Nat. Rev. Mol. Cell Biol. 8: 275-283.

Wang, X., Tang, S., Le, S.Y., Lu, R., Rader, J.S., Meyers, C., and Zheng, Z.M. 2008. Aberrant expression of oncogenic and tumorsuppressive microRNAs in cervical cancer is required for cancer cell growth. PLoS One 3: e2557. doi: 10.1371/journal.pone.0002557.

Wang, H.-K., Duffy, A., Broker, T.R., and Chow, L.T. 2009. Robust production and passaging of infectious HPV in squamous epithelium of primary human keratinocytes. Genes \& Dev. 23: 181-194.

Welch, C., Chen, Y., and Stallings, R.L. 2007. MicroRNA-34a functions as a potential tumor suppressor by inducing apoptosis in neuroblastoma cells. Oncogene 26: 5017-5022.

Wilson, J.L., Dollard, S.C., Chow, L.T., and Broker, T.R. 1992. Epithelial-specific gene expression during differentiation of stratified primary human keratinocyte cultures. Cell Growth Differ. 3: $471-483$.

Yamamoto, H., Soh, J.W., Monden, T., Klein, M.G., Zhang, L.M., Shirin, H., Arber, N., Tomita, N., Schieren, I., Stein, C.A., et al. 1999. Paradoxical increase in retinoblastoma protein in colorectal carcinomas may protect cells from apoptosis. Clin. Cancer Res. 5: $1805-1815$.

Yi, R., O'Carroll, D., Pasolli, H.A., Zhang, Z., Dietrich, F.S., Tarakhovsky, A., and Fuchs, E. 2006. Morphogenesis in skin is governed by discrete sets of differentially expressed microRNAs. Nat. Genet. 38: 356-362.

Zhang, Z., Borecki, I., Nguyen, L., Ma, D., Smith, K., Huettner, P.C., Mutch, D.G., Herzog, T.J., Gibb, R.K., Powell, M.A., et al. 2007. CD83 gene polymorphisms increase susceptibility to human invasive cervical cancer. Cancer Res. 67: 11202-11208. 

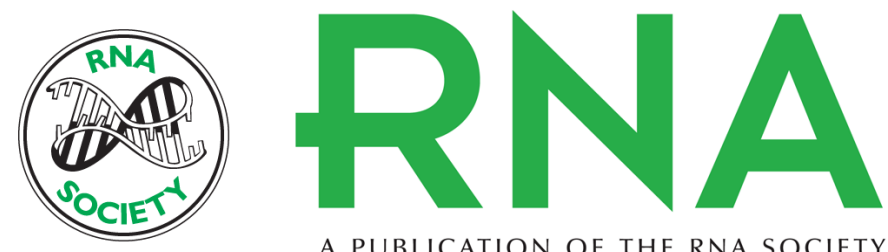

A PUBLICATION OF THE RNA SOCIETY

\section{Oncogenic HPV infection interrupts the expression of tumor-suppressive miR-34a through viral oncoprotein E6}

Xiaohong Wang, Hsu-Kun Wang, J. Philip McCoy, et al.

RNA 2009 15: 637-647 originally published online March 3, 2009

Access the most recent version at doi:10.1261/rna.1442309

\section{References This article cites 58 articles, 30 of which can be accessed free at: http://rnajournal.cshlp.org/content/15/4/637.full.html\#ref-list-1}

Open Access Freely available online through the RNA Open Access option.

License Freely available online through the open access option.

Email Alerting Receive free email alerts when new articles cite this article - sign up in the box at the Service top right corner of the article or click here. 